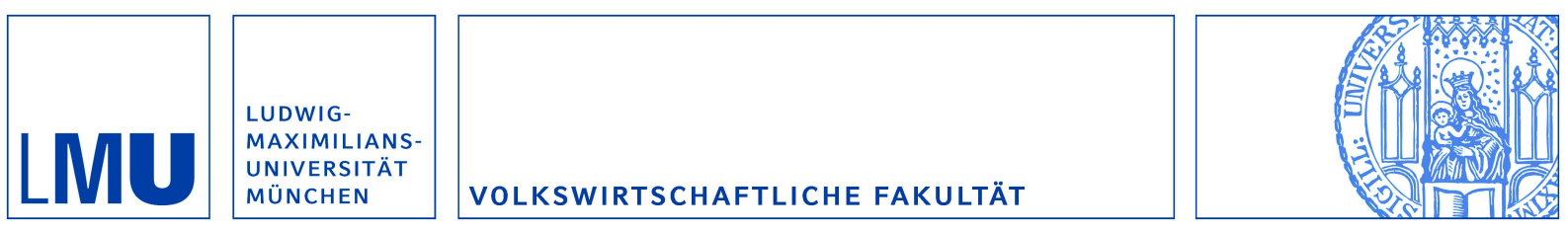

Schlicht, Ekkehart:

A Case Where Barro Expectations Are Not Rational

Munich Discussion Paper No. 2012-4

Department of Economics

University of Munich

Volkswirtschaftliche Fakultät

Ludwig-Maximilians-Universitäł München

Online at https://doi.org/10.5282/ubm/epub. 12715 


\title{
A Case Where Barro Expectations Are Not Rational
}

\author{
Ekkehart Schlicht*
}

\begin{abstract}
This note generalizes Feldstein's (1976) criticism of Barro's(1974) analysis for the case that the interest rate exceeds the growth rate. This is done by considering an economy in steady state where all agents hold "Barro expectations": they believe that government debt must necessarily be repaid and therefore leave the present value of their income streams unchanged. In this scenario, a change in the mode of taxation affects the present value of disposable income in the private sector. This violates their Barro expectations.

Keywords: Barro-Ricardo equivalence, Ricardian equivalence, fiscal policy, debt, taxation, rational expectations

Journal of Economic Literature Classification: E2, E12, E6, H6
\end{abstract}

*Ekkehart Schlicht (schlicht@1mu.de) is professor emeritus of economics at the University of Munich, Germany. 


\section{Introduction}

Feldstein (1976) has shown that a permanent government deficit may increase the present value of the households' income if the rate of growth exceeds the rate of interest. The present note generalizes Feldstein's remarks to the case that the rate of interest exceeds the rate of growth. In this sense, it invalidates Barro's (1974) analysis also for that case. The generalization is proved by presenting an example of an economy in steady state where government decides to reduce taxation and generate a permanent deficit. All members of the private sector hold "Barro expectations": they believe that government debt must necessarily be repaid and the present value of their income streams remain unchanged. Hence they do not change their expenditure. It is shown that the policy switch from a pay-as-you-go regime to a deficit regime increases the present value of disposable income in the private sector, contrary to Barro's assertion.

In this sense the example disproves the logic of Barro's interpretation of Ricardian equivalence.

\section{An Example}

Consider a closed economy that grows with the nominal rate $g$. Gross income at time $t$ is $Y_{t}$, private expenditure (consumption plus investment) is $E_{t}$, taxes are $T_{t}$ and government expenditure is $G_{t}$. Let $D_{t}$ denote government debt. Initially there is no government debt:

$$
D_{0}=0 .
$$

Income and government expenditure grow both with rate $g$. So we have

$$
\begin{aligned}
Y_{t} & =(1+g)^{t} Y_{0} \\
G_{t} & =(1+g)^{t} G_{0}
\end{aligned}
$$

The economy is initially in full equilibrium with an interest rate $i>g$ and private expenditure $E_{0}$. Private expenditure $E$ and government expenditure $G$ add 
up to total production, and the expectation held by all parties is that this will continue in the future:

$$
E_{t}+G_{t}=Y_{t}
$$

Up to $t=-1$, the government budget was balanced, and the taxes levied in any period $t<0$ were equal to government spending $G_{t}$ in that period. Call this the "pay-as-you-go regime." All parties have expected and expect that this policy would continue throughout the future, but government changes its policy and decides to run a permanent deficit of a fraction $\alpha \in(0,1)$ of its expenditure $G_{t}$ in each period, beginning at $t=0$ while leaving government expenditure $G_{t}$ unchanged. So government expenditure remains as described in equation (10). Call this the "debt regime."

In line with Barro's $(1974 ; 1989)$ analysis, the households and firms expect that the change in policy does not affect the present value of their liftime income stream. Hence they believe that "rearrangements of the timing of taxes - as implied by budget deficits - have no first-order effect on the economy" (Barro, 1989, 51). They conclude that, sooner or later, the government has to increase taxes, leaving the present value of their incomes unaltered. So they change neither consumption nor investment. In short, everybody in the private sector holds "Barro expectations" and behaves accordingly. (It will turn out, however, that these expectations will not be fulfilled.)

In each period $t=0,1,2 \ldots$ the deficit is $\alpha G_{t}$, and outstanding government debt $D$ increases in each period by this amount. Therefore we have

$$
\begin{aligned}
D_{0} & =0 \\
D_{t+1} & =D_{t}+\alpha G_{t} .
\end{aligned}
$$

This implies together with (3).

$$
D_{t}=\frac{\left((1+g)^{t}-1\right)}{g} \alpha G_{0} \text {. }
$$

So debt grows asymptotically in proportion with production. The ratio of government debt to government expenditure approaches $\alpha / g$ and the ratio of government 
debt to production approaches $\alpha / g$ times the share of government expenditure in total production.

$$
\lim _{t \rightarrow \infty} \frac{D_{t}}{G_{t}}=\frac{\alpha}{g}, \lim _{t \rightarrow \infty} \frac{D_{t}}{Y_{t}}=\frac{\alpha}{g} \cdot \frac{G_{0}}{Y_{0}} .
$$

The present value of government debt is

$$
\begin{aligned}
V & =\sum_{t=0}^{\infty}\left(\frac{1}{1+i}\right)^{t} D_{t} . \\
& =\frac{1}{i} \frac{1+i}{(i-g)} \alpha G_{0}
\end{aligned}
$$

As $i>g$ is assumed, the present value of the debt is a positive number (less than infinity), although debt is never retired.

The deficit in period 0 is $\alpha G_{0}$. It is entailed by the tax reduction of the same size. So we have tax receipts of $T_{0}=(1-\alpha) G_{0}$ in period 0 . In period 1 government debt is $D_{1}=\alpha G_{0}$. This requires interest payments $i D_{1}$. The deficit in period 1 is the sum of government expenditure $G_{1}$ plus interest payments $i D_{1}$ minus tax receipts $T_{1}$. The deficit is to be $\alpha G_{1}$. Hence we have

$$
G_{1}+i D_{1}-T_{1}=\alpha G_{1}
$$

A similar consideration applies to all periods:

$$
G_{t}+i D_{t}-T_{t}=\alpha G_{t}
$$

Solving for $T_{t}$ gives the amount of taxes to be collected in period $t$ :

$$
T_{t}=(1-\alpha) G_{t}+i D_{t}
$$

Furthermore, the ratio of taxes to production approaches

$$
\lim _{t \rightarrow \infty} \frac{T_{t}}{Y_{t}}=\frac{g+(i-g) \alpha}{g} \cdot \frac{G_{o}}{Y_{o}}>\frac{G_{o}}{Y_{o}} .
$$

The government collects higher taxes under the debt regime than under the pay-asyou-go regime. 
Now consider the households. If the government would run a balanced budget all the time, their discounted disposable income would have been

$$
\begin{aligned}
W & =\sum_{t=0}^{\infty}\left(\frac{1}{1+i}\right)^{t}\left(Y_{t}-G_{t}\right) \\
& =\left(Y_{0}-G_{0}\right) \sum_{t=0}^{\infty}\left(\frac{1+g}{1+i}\right)^{t} \\
& =\frac{1+i}{i-g}\left(Y_{0}-G_{0}\right) .
\end{aligned}
$$

The debt policy, however, results in disposable income

$$
Z_{t}=Y_{t}-T_{t}+i D_{t}
$$

which is

$$
\begin{aligned}
Z_{t} & =(1+g)^{t}\left(Y_{0}-(1-\alpha) G_{0}\right) \\
& =Y_{t}-(1-\alpha) G_{t}>Y_{t}-G_{t} .
\end{aligned}
$$

Under the pay-as-you-go regime, disposable income in each period would have been $Y_{t}-G_{t}$. Hence the switch from the pay-as-you-go regime to the debt regime has increased disposable income for all periods by the fraction $\alpha$ of government expenditure $G_{t}$.

The present value of disposable income is

$$
Q=\sum_{t=0}^{\infty}\left(\frac{1}{1+i}\right)^{t} Z_{t} .
$$

This is calculated as

$$
Q=\frac{1+i}{i-g} \cdot\left(Y_{0}-(1-\alpha) G_{0}\right)
$$

The difference between this present value of disposable income under the debt regime and the corresponding present value under the pay-as-you-go regime (13) is

$$
Q-W=\frac{1+i}{i-g} \alpha G_{0}>0 .
$$


Hence the present value of the household's lifetime income has increased by switching from a pay-as-you-go regime to the deficit regime. The Barro expectations held by the subjects are not fulfilled.

As the value of their lifetime income stream has increased, they could have afforded higher expenditure, with more consumption and more investment, but this would have presumably affected the rate of interest and the value of production and income in turn. Hence the assumption (2) - which is a cornerstone of Barro's (1974) analysis - can not usefully be upheld. ${ }^{1}$

\section{Conclusion}

It has been urged elsewhere that Ricardian equivalence in Barro's(1989) interpretation is quite irrelevant regarding fiscal policy (Schlicht, 2006, Sect. 9). The above example points out that Barro's view is internally contradictory. In conclusion, arguments alluding to "Ricardian equivalence" in Barro's interpretation ought not to be applied to real economies. Despite their apparent logical appeal such arguments are misleading, not only empirically, but also theoretically (Romer, 1995, 72).

\section{References}

Barro, R. J. (1974). Are Government Bonds Real Net Wealth? Journal of Political Economy, 82(6): 1095-1117. URL http://www.jstor.org/pss/1830663.

Barro, R. J. (1989). The Ricardian Approach to Budget Deficits. The Journal of Economic Perspectives, 3(2): 37-54. URL http://www.jstor.org/pss/1942668.

Feldstein, M. (1976). Perceived Wealth in Bonds and Social Security. Journal of Political Economy, 84(2): 331-36. URL http://www.jstor.org/pss/1831904.

Romer, D. (1995). Advanced Macroeconomics. McGraw-Hill. URL http://www. amazon.de/dp/0070536678.

\footnotetext{
1 For the sake of completeness I note that the present value of government debt exceeds the present value of disposable income if $\alpha<\frac{i\left(Y_{0}-G_{0}\right)}{(1+i) G_{0}}$ is satisfied.
} 
Schlicht, E. (2006). Public Debt as Private Wealth. Metroeconomica, (4): 594-520. URL http://epub.ub.uni-muenchen.de/2143/1/schlicht-public-debt-13-RP.pdf. 
Mathematica notebook with the calculations for A Case Where Barro Expectations Are Not Rational by Ekkehart Schlicht

- Income $Y$ and Government expenditure G (Eqs. 2 and 3)

$$
\begin{aligned}
\ln [1]:= & \mathbf{Y}\left[\mathrm{t}_{-}\right]:=(1+g)^{\mathrm{t}} \mathbf{Y}_{0} ; \\
& \mathbf{G}\left[\mathrm{t}_{-}\right]:=(1+g)^{\mathrm{t}} \mathbf{G}_{0} ;
\end{aligned}
$$

- Government debt (Eqs. 5 to 7)

$$
\begin{aligned}
\operatorname{In}[3]:= & \operatorname{Clear}[d] ; \\
& \text { RSolve }[\{d[t+1]=d[t]+\alpha G[t], d[0]=0\}, d[t], t] \\
\operatorname{Out}[4]= & \left\{\left\{d[t] \rightarrow \frac{\left(-1+(1+g)^{t}\right) \alpha G_{0}}{g}\right\}\right\} \\
\operatorname{In}[5]:= & d\left[t_{-}\right]:=\frac{\left(-1+(1+g)^{t}\right) \alpha G_{0}}{g}
\end{aligned}
$$

- Asymptotic ratio of debt to government expenditure (Eq.8)

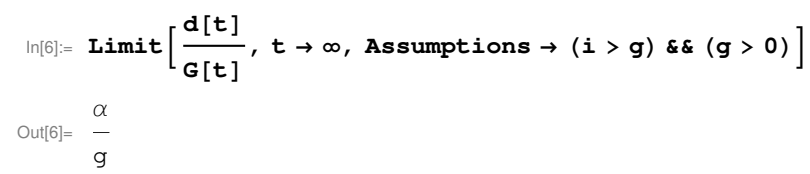

- Asymptotic ratio of debt to production (Eq. 8)

$\ln [7]:=\operatorname{Limit}\left[\frac{d[t]}{Y[t]}, t \rightarrow \infty\right.$, Assumptions $\left.\rightarrow(i>g) \& \&(g>0)\right]$ Out $[7]=\frac{\alpha G_{0}}{g Y_{0}}$

- Present value of goverment debt (Eq. 9)

$$
\begin{aligned}
\ln [8]:= & \mathbf{V}=\sum_{\mathbf{t}=0}^{\infty}\left(\frac{1}{1+i}\right)^{\mathbf{t}} \mathbf{d}[\mathbf{t}] \\
\text { Out[8]=} & -\frac{(1+i) \alpha G_{0}}{(g-i) i} \\
& -\frac{(1+i) \alpha G_{0}}{(g-i) i}
\end{aligned}
$$

- Taxes (Eq. 11)

$$
\ln [9]:=\mathbf{T}\left[\mathrm{t}_{-}\right]:=(1-\alpha) \mathrm{G}[\mathrm{t}]+\mathbf{i d}[\mathrm{t}]
$$

- Asymptotic ratio of taxes to income (Eq. 12)

$$
\begin{aligned}
& \ln [10]:=\operatorname{Limit}\left[\frac{\mathbf{T}[\mathbf{t}]}{\mathbf{Y}[\mathbf{t}]}, \mathbf{t} \rightarrow \infty, \text { Assumptions } \rightarrow(\mathbf{i}>\mathbf{g}) \& \&(\mathbf{g}>\mathbf{0})\right] \\
& \text { Out[10]}=-\frac{(g(-1+\alpha)-i \alpha) G_{0}}{g Y_{0}} \\
& \ln [11]:=\text { Simplify }\left[\%==\frac{(\mathbf{g}+(\mathbf{i}-\mathbf{g}) \alpha) G_{0}}{\mathbf{g} \mathbf{Y}_{0}}\right] \\
& \text { Out[11]= True }
\end{aligned}
$$


- Household wealth with balanced budget (Eq. 13)

$\ln [12]:=\mathbf{W}=\operatorname{Simplify}\left[\sum_{t=0}^{\infty}\left(\left(\frac{1}{1+i}\right)^{t}(Y[t]-G[t])\right)\right]$

Out[12] $=\frac{(1+i)\left(G_{0}-Y_{0}\right)}{g-i}$

- Disposable income (Eqs. 14 and 15)

$\ln [13]:=\mathbf{Z}\left[t_{-}\right]:=\mathbf{Y}[t]-\mathbf{T}[t]+\mathbf{i}[t]$

$\ln [14]:=\mathbf{z}[\boldsymbol{t}]$

Out[14]= $-(1+g)^{t}(1-\alpha) G_{0}+(1+g)^{t} Y_{0}$

- Present value of disposable income (Eq. 16)

$\ln [15]:=$

$\ln [16]:=Q=\operatorname{Simplify}\left[\sum_{t=0}^{\infty}\left(\left(\frac{1}{1+i}\right)^{t}(z[t])\right)\right]$

Out[16]= $-\frac{(1+i)\left((-1+\alpha) G_{0}+Y_{0}\right)}{g-i}$

- Difference of present values (Eq. 17)

$\ln [17]:=$

Simplify $[Q-W]$

Out[17] $=-\frac{(1+i) \alpha G_{0}}{g-i}$

- Condition for $Q>V$ (Footnote 1)

$\ln [18]:=$ Simplify $[\mathbf{Q}-\mathbf{V}]$

Out[18] $=-\frac{(1+i)\left((i(-1+\alpha)-\alpha) G_{0}+i Y_{0}\right)}{(g-i) i}$

$\ln [19]:=\operatorname{Simplify}\left[\%==\frac{(1+i)}{(i-g) i}\left(i\left(Y_{0}-G_{0}\right)-(1-i) \alpha G_{0}\right)\right]$

Out[19]= True

$\operatorname{In}[20]:=\operatorname{Reduce}\left[\left\{\left(i\left(Y_{0}-G_{0}\right)-(1-i) \alpha G_{0}\right)>0, g>i, i>0, \alpha>0, \alpha<1, Y_{0}>G_{0}, G_{0}>0\right\}, \alpha, \operatorname{Reals}\right]$

Out[20]= $G_{0}>0 \& \& Y_{0}>G_{0} \& \&\left(\left(0<i \leq \frac{G_{0}}{Y_{0}} \& \& g>i \& \& 0<\alpha<\frac{i G_{0}-i Y_{0}}{-G_{0}+i G_{0}}\right)||\left(i>\frac{G_{0}}{Y_{0}} \& \& g>i \& \& 0<\alpha<1\right)\right)$ 